\title{
Arquivos do CMD De Ben a Ben Jor: hibridismo e trânsitos simbólicos na trajetória do cantor Jorge Ben Jor
}

Marcos Henrique Amaral ${ }^{* *}$
Texto
referente
comunicação homônima
proferid
dezembro de 2015, durante
XIX Seminário Interno de
Pesquisa do Grupo Cultura,
Memória e Desenvolvimento (CMD/UnB).
Aluno de doutorado no
Programa de Pós-Graduação
em Sociologia da Universidade
de Brasília (PPG-SOL/UnB)
Bolsista CAPES. E-mail:
marcoshenriquesa@gmail.com

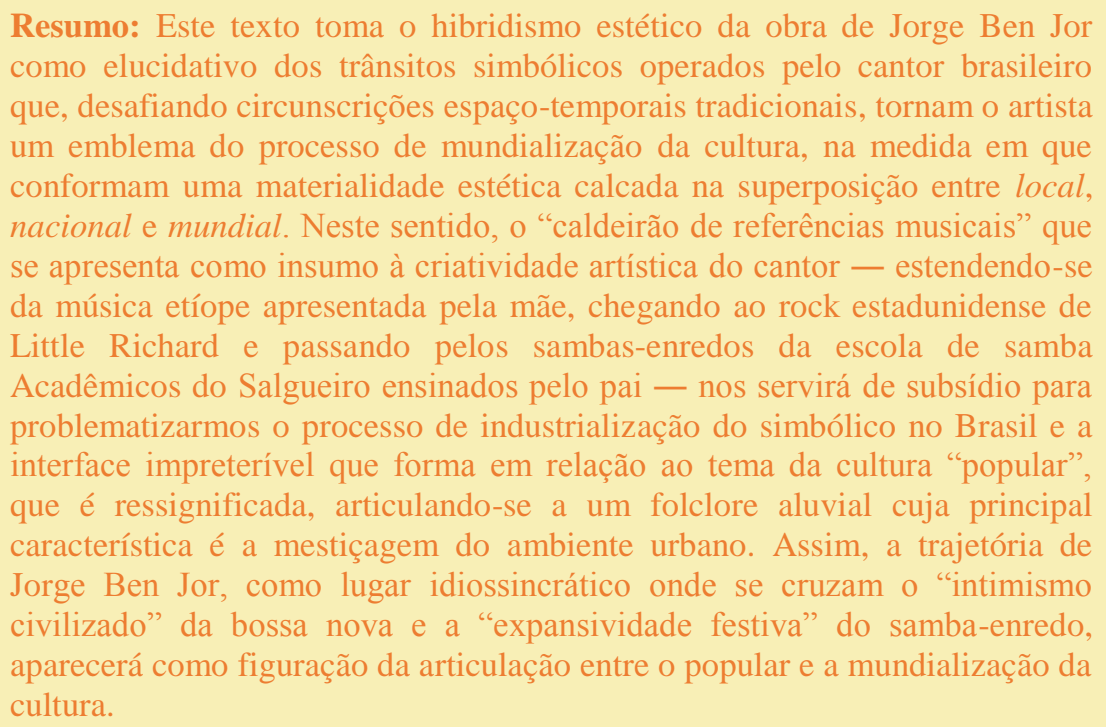




\section{INTRODUÇÃO}

É fenômeno mesmo, pois desde há muito não aparecia ninguém como ele no meio artístico verde-amarelo. De um único disco de 78 RPM, irrompeu abruptamente a torrente irresistível do sucesso. E sucesso bom, sem "apelações" comerciais ou duvidosas concessões artísticas. Tudo bem "brasileirão", tudo autêntico e, o que é importante, inteligentemente apresentado, dentro do processo evolutivo por que passa a música popular brasileira. É o esquema novo do samba.

A epígrafe acima consta na contracapa do disco "Samba Esquema Novo" de Jorge Duílio Lima Menezes — Jorge Ben até 1988 e Jorge Ben Jor até os dias de hoje —, lançado em 1963. O parágrafo citado é sucedido por uma série de descrições que buscavam definir, de forma irresoluta, um gênero musical para o cantor debutante: o artista seria um artífice do "retorno à nossa música popular primitiva", porém com "características modernas". O texto ainda menciona a influência "negroide" em suas composições, e afirma que o "samba esquema novo" de Jorge Ben é uma música moderna diferente da "bossa nova dos primeiros tempos", cujo precursor mais célebre é João Gilberto, apesar das semelhanças no cantar de ambos. A indefinição acerca do estilo musical a qual Jorge Ben se filiaria é uma constante até mesmo no discurso do próprio cantor que, em entrevista ao programa televisivo Roda Viva, diz que sua música é "uma mistura; fui misturando".

O hibridismo estético - que também define a singularidade da obra desta personagem da música brasileira — já foi tema, também, de trabalhos acadêmicos, tal qual a dissertação de mestrado "Para animar a festa: a música de Jorge Ben Jor", de Alam D’Ávila do Nascimento (2008) e o artigo “África Brasil: uma análise midiática do álbum de Jorge Ben Jor”, de Luciana Xavier Oliveira (2012). O norte de ambos os trabalhos parece ser a compreensão do estilo composicional-interpretativo do artista, dedicando-se a uma análise estético-musical que o filia a diversas nomenclaturas: bossanova, samba-jazz, samba, rock, tropicalismo, jovem guarda, pop, soul, funk, blues, samba-rock. Nascimento (2008, p. 19), ao se referir sobre o ambiente musical em que Jorge Ben inicia sua carreira musical, diz que o cantor é influenciado por um "caldeirão de referências musicais".

Para além da análise estético-musical, já operada pelos dois autores supracitados, a dificuldade de se definir um gênero musical para a obra de Jorge Ben decorre do fato de que tais categorias - a despeito de seu didatismo - acabam por velar o caráter processual da trajetória artística do cantor ( $c f$. ELIAS, 1970; 1995). Destarte, a multiplicidade de categorias às quais poderíamos associar a personagem em questão só teria valor sociológico para apontar o trânsito de referentes simbólicos amalgamados por suas composições. Trânsito este que elucida processos de longa duração sócio-histórica tais quais a construção de uma identidade nacional, a modernização cultural e a industrialização do simbólico — tomada como contrapartida da triangulação entre urbanização, industrialização e incremento no setor de serviços, mas posta no 
Do ponto de vista metodológico, as mudanças no padrão de criação/produção artística podem ser paradigmáticas para elucidar as mudanças na configuração sócio-histórica. Ora, é isto que buscamos fazer: por um lado, olha-se para a obra de Jorge Ben Jor e entende-se a configuração e os processos por outro lado, olha-se para a configuração para entender a obra. plano dos modos de simbolização e expressão, na medida em que se monta uma sistemática de comunicação massiva no Brasil. Deste modo, a análise da trajetória de Jorge Ben sai do plano meramente estético-musical e passa ao plano sócio-histórico: deixa-se de lado a tentativa de enquadrar uma obra marcadamente híbrida em um gênero musical, e toma-se o artista como um processo psicossocial, com uma trajetória-corpo que vai se constituindo a partir de diversos feixes de processos.

Seguindo o rastro deixado por sociobiografias realizadas por Elias (1995), Alves (2012) e Amaral (2012), este texto busca analisar a trajetória de Jorge Ben - em última instância, sua biografia - à maneira de uma personagem paradigmática das tramas de interdependências sócio-funcionais que envolvem a consolidação de uma sociedade de consumo e de uma cultura popular de massa no Brasil, com suas repercussões nas criações de Jorge Ben e, ademais, com as reverberações da obra do artista na produção cultural subsequente. Algo em referência à própria relação dialética entre criação - o "fluxo-fantasia" - e produção (MORIN, 2009, p. 140) Deste modo, retoma-se o próprio caráter processual da configuração da qual estamos falando e para a qual Elias chama a atenção, em seus estudos sobre Mozart, mostrando - a todo instante - que mudanças sociais incidem sobre a criação artística, possibilitando mudanças do padrão de criação/produção artística ${ }^{1}$ (cf. ELIAS 1995).
Para fazer este elo entre o caráter subjetivo e objetivo da vida e da obra de Jorge Ben Jor, este artigo intenta esboçar um modelo teórico da configuração sócio-histórica que esta personagem — um músico que inicia sua carreira no Brasil da década de 1950 formava e ainda forma com outras figuras sociais durante sua carreira. Esta delimitação apresenta, de um lado, o próprio remanejamento da sociedade nacional como estrutura urbanoindustrial, e a conseqüente consolidação de uma sociedade de consumidores, nos anos 1960; e de outro lado, a conformação do espaço social da música popular no Brasil, em que a figura de Jorge Ben Jor parece catalisar cruzamentos de gêneros tradicionais como os sambas-enredos da Salgueiro e a música etíope apresentada pela mãe - com aqueles referentes à tradição do pop - em especial o rock. Não importa, portanto, para este trabalho, o quão incomparáveis são as realizações individuais de Jorge Ben Jor, mas sim a elaboração de um quadro das interdependências sóciofuncionais que elencam o indivíduo à condição de símbolo perene da música nacional. Em contrapartida, a construção de sua trajetória artística pode ser tomada como um processo adjacente e elucidativo dos processos configuracionais, como a mundialização da cultura e a hibridização entre topologias locais, nacionais e mundiais.

\section{Trânsitos o nacional-popular e o internacional-popular}


2 Não foram encontradas informações sobre a profissão da mãe de Jorge Ben Jor. Em entrevista concedida à Revista Trip, em novembro de 2009, ao ser indagado sobre "o que seus pais faziam", o cantor é omisso, limitando-se a explanar a respeito do pai: "De meu pai aprendi a malandragem e o lado filósofo. Meu pai foi um grande
estivador. Tinha um Ford bigode, um caminhão, e o orgulho dele era domingo levar o pessoal pro futebol pra piquenique. Trabalhou de pra piquenique. Trabathou de estivador e quando se aposentou fez parte do bonvivant da zona sul, morava em Copacabana, ia à praia pescar".

${ }^{3}$ Nas leituras em função da confecção deste projeto pesquisa, este termo fo marcadamente usado por Augusto de Campos (2008) Augusto de Campos (2008)
para referir-se ao popularurbano como cultura: uma cultura nova que procede por apropriações polimorfas junto com o estabelecimento de um mercado musical onde o popular em transformação convive com dados da música internacional e do cotidiano da cidade, além dos mecanismos técnicos de reprodução e difusão desta cultura. Ele

Dossiê Multimodalidade da Memória: Narrativa e Teoria Social

Arquivos do CMD, Volume 4, N.1. Jan/Jun 2016
Nascido em 1942, quando a capital do país parecia magnetizar grande parte do potencial de urbanização nacional, Jorge Duílio Lima Menezes, conhecido popularmente como Jorge Ben ou Jorge Ben Jor, integrava a população negro-mestiça que habitava o bairro do Rio Comprido, zona norte carioca. Seu pai, Augusto Menezes, estivador e feirante, e sua mãe, Silvia Saint Ben de Lima ${ }^{2}$ são apontados no programa televisivo "Roda Viva" (1995) como alguns dos responsáveis pelo seu aprendizado musical. Com seu pai - também pandeirista, cantor e compositor carnavalesco aprendeu a gostar das escolas de samba: "O meu pai me levou pela primeira vez no Salgueiro para ver, eu gostei, era uma coisa diferente. Eu sempre gostei de percussão e a primeira vez que eu vi um maestro de escola de samba, eu achei incrivel". Na mesma balança das referências musicais, o cantor insere a música do rádio - ouvia desde o samba de Ataulfo Alves ao baião de Luiz Gonzaga —, os aprendizados no seminário onde estudara, e a música africana apresentada pela mãe, filha de etíopes: “(...) eu ouvi muita música etíope através da minha mãe, com batuques dos parentes. Eu era menino, criança, e ouvia o som, eles falavam numa língua que eu não entendia e um batuque, isso foi misturando tudo". Some-se a este "caldeirão de referências musicais", os grandes ídolos do cantor João Gilberto — que no fim dos anos 1950 tornava-se notável pela mistura que faz entre samba e jazz, apelidada de bossa nova - e Little Richards, cantor e pianista negro de rock estadunidense.
A heterogeneidade dos insumos musicais aponta que a trajetória de Jorge Ben Jor, desde sua infância é marcada pelo cruzamento de gêneros associados a matrizes assaz distintas. Seu aprendizado musical é dado sob o registro daquilo que MartinBarbero (2009) chama de "folclore aluvial", uma espécie de "folclore urbano" " que se apresenta como mosaico de inspirações heterogêneas associadas ao fluxo nacional e transnacional de referentes simbólicos; uma "mestiçagem" típica do ambiente urbano, marcada por permanências, novidades e rupturas. É ponto pacífico na literatura sobre o tema da indústria cultural e da industrialização do simbólico ${ }^{4}$ que os anos 1940 e 1950 - marcados pela intensificação dos processos de urbanização e industrialização, cujos epicentros encontram-se no eixo Rio-São Paulo - registram a incipiência de uma montagem de uma sistemática de comunicação massiva no Brasil ${ }^{5}$. Estes processos sócio-técnicos de produção e transmissão de signos, imagens e sons, em larga escala capitaneados especialmente pela indústria fonográfica e pelo rádio, que Jorge Ben Jor ouvia com seu pai durante a infância, e posteriormente pela televisão, que tem papel fundamental durante os anos 1960 - não apenas se apresentam como "fornecedores" de novos insumos musicais como aceleram os trânsitos simbólicos de matrizes locais, nacionais e transnacionais.

Destaco as contribuições de Renato Ortiz (2009) e Michel De Certeau (1994) que apresentam uma noção de espacialidade e transversalidade entre os feixes nacional e 
utiliza a noção de "folclore urbano" neste sentido, afirmando que o caminho tomado pela MPB - ao tomar um "folclore artificial" como insumo de sua obra, buscando afirmar certa impermeabilidade nacional face ao movimento transnacional de símbolos deveria ser revisto neste sentido, sob pena de perder sua popularidade face ao "iê-iê-iê" brasileiro.

Para os frankfurtianos Adorno e Horkheimer (1985), a indústria cultural nas sociedades de massa seria o prolongamento das técnicas utilizadas na indústria fabril, o que significa que ela apresentaria um propósito fundamental: vender produtos. Ou seja, ela não apresenta mais a música ou o cinema com arte e sim como um negócio, passando a reger-se pelas leis do mercado. A arte submete-se

à face comercial da indústria cultural de maneira tal que acaba por reduzir-se

5 Cf. Ortiz (2006) e Mira (2001)

6 Interessante salientar a interface deste processo de transnacional - que em outras obras aparecerão sob alcunhas de "popular-nacional” e "internacional popular" (ORTIZ, 2006) de modo a dar conta de tais trânsitos simbólicos, cuja origem pode ser encontrada na triangulação entre os processos de urbanização, industrialização e incremento do setor de serviços, na qual a industrialização do simbólico constitui justamente o plano dos modos de simbolização e expressão. O primeiro autor apresenta uma noção de espacialidade definida pela superposição entre local, nacional e mundial, que constituem feixes independentes, mas igualmente interdependentes, cujo relacionamento acontece de maneira transversal, de modo tal que o espaço - convertendo-se em lugar - deve ser visto a partir do prisma dos atravessamentos mútuos entre os feixes. Ou seja, o nível do mundial não é necessariamente totalizador, embora haja desigualdades em sua conjunção com os níveis local e nacional. Interessa observar que, no entrelaçamento de tais instâncias, o espaço converte-se em lugar que é, em si mesmo, o lugar da idiossincrasia, da diferencialidade. Sumariamente, o autor sugere que:

(...) local, nacional e mundial devem ser vistos no seu atravessamento. O lugar seria então o cruzamento de diferentes linhas de força no contexto de uma situação determinada. (...) situação definida objetivamente pelas forças sociais, portadoras de legitimidades desiguais, no seio da qual os homens atuam. Local, nacional e mundial se entrelaçam, portanto, de formas diversas, determinando o quadro social das especialidades em conjunto. Este quadro irá variar segundo os contextos e, sobretudo, em função da prevalência, ou não, de determinados pré-requisitos tecnológicos e econômicos - a modernidade-mundo não se reduz ao movimento de "modernização" das sociedades, e sim os acompanha. Com isso, quero dizer que o nacional e o local são penetrados pela mundialização. Pensá-los como unidades autônomas seria inconsistente. Porém, como a base materia da modernidade-mundo é desigual, e a expansão da cultura deve obrigatoriamente levar em conta a diversidade dos povos, sua conjunção só pode ocorrer como diferencial. O lugar é o espaço da diferencialidade (ORTIZ, 2009, pp. 6566).

Seguindo o rastro deixado por Ortiz, e a título de organização conceitual, poderemos enxergar o primeiro registro fonográfico de Jorge Ben Jor, intitulado "Samba Esquema Novo", a partir da categoria tática, tal qual pontuada por Michel De Certeau (1994) na obra “A invenção do cotidiano". Este recurso conceitual, nos ajuda a entender como a trajetória de Jorge Ben Jor se apresenta como ponto de cruzamento entre gêneros de música tão diversos quanto o samba-enredo, o samba-canção, a bossa-nova, o rock e as batucadas etíopes que ele "herda" de sua mãe. A categoria aparece como reaproveitamento simbólico ou ressignificação de símbolos que, na aparência, podem denotar aceitação dos padrões hegemônicos, mas que na realidade representam outros valores: aí está o lugar da idiossincrasia, o ponto de intersecção do atravessamento entre local, nacional e mundial ${ }^{6}$. Ao fazer análise estético-musical da faixa "Mas que nada", presente no registro de 1963, Nascimento (2008) observa que há, ali, características típicas bossa nova, do samba, do rock, do blues e do soul. O pesquisador também dá relevo ao "sangue africano", elucidado pelo uso 
atravessamento espacial com o processo de mundialização cultural, também trabalho por Ortiz (1996). Neste sentido, a industrialização do simbólico, ao acelerar os fluxos informacionais - locais, nacionais e transnacionais - e gestar um mercado de bens simbólicos, aparece como um agente da mundialização, entendida como a conjunção idiossincrática dessa espacialidade multifacetada.

7 Tradução livre para: "Since the early 1960's, Mr. Ben has been making connections between Brazilian, Caribbean, North American and African music - adding the kick of rock and African-Brazilian rhythms to the sophisticated lilt of the bossa nova".

${ }^{8}$ cf. Alves (2011); Ulhôa (1997); Napolitano (2010). sistemático modo menor, sobre o qual o cantor viria afirmar, no programa Roda Viva (1995): “A minha música é sempre triste porque sempre usei tom menor. Isso é uma coisa que aprendi desde cedo. O tom menor é melodioso, mas ele é muito triste. Aí você vai fazendo até achar uma solução”. A solução que ele encontra parece estar no ritmo do samba-enredo e a forte marca dançante que, segundo Nascimento (2008), também são constantes na obra do artista. A hibridização é uma recorrência na trajetória artística de Jorge Ben Jor - certamente formada pelas memórias deste folclore aluvial, que conjuga, initerruptamente, o antigo e o novo, o nacional e o mundial. Já em 1986, 23 anos após o lançamento do primeiro disco de Jorge Ben Jor, o New York Times destaca que "desde o início dos anos 1960, o senhor Ben vem fazendo conexões entre música brasileira, caribenha, norte-americana e africana adicionando o ímpeto do rock e dos ritmos afro-brasileiros à cadência sofisticada da bossa nova" $"$.

Neste sentido, não seria errôneo afirmar que Jorge Ben Jor aparece como personagem elucidativa da intensificação dos trânsitos entre nacional e internacional promovida pela industrialização do simbólico; com uma criação artística que se apresenta como tática, contemporizando matrizes culturais vinculadas a diversas espacialidades, ressignificando-as, criando idiossincrasia. É neste sentido que Ortiz (2009) e Certeau (1994) subsidiam a hipótese segundo a qual, a partir de insumos musicais já existentes e provindos de diversos feixes espaciais, o artista cria uma diferencialidade: a trajetória de Jorge Ben Jor só poderá ser vista como resultado deste processo de desencaixe espaço-temporal da modernidade (GIDDENS,1991), mas simultaneamente como marcadora do processo de rearticulação das identidades nacionais, agora necessariamente tributárias do relacionamento entre diversas espacialidades.

É válido salientar, no entanto, que essa diferencialidade híbrida não é operada de forma harmoniosa. A despeito da hipótese contida em obras de frankfurtianos como Lowenthall (1950), Adorno e Horkheimer (1985), segundo a qual uma suposta univocidade social seria criada pelo avanço progressivo da racionalidade tecnomercantil, diversos autores ${ }^{8}$ — indo na direção inversa apontam que o processo de industrialização do simbólico no Brasil acaba por fazer visível a música popular e o processo de construção da identidade nacional como espaços topológico de conflitos profundos que perduram historicamente na nossa contemporaneidade, embora de forma "domesticada" (ORTIZ, 2006). Isto porque, no processo de modernização brasileiro, o avanço dos dispositivos sócio-técnicos de produção e difusão de sons e imagens não logra êxito imediato em estabelecer uma univocidade no mercado de bens simbólicos, ou seja, não representa a abolição do caractere político. É neste sentido que o domínio da técnica, de pretenso caráter neutro, se converte em um terreno de luta cujos traços heurísticos são a televisão com os programas "Jovem Guarda" e "O Fino da Bossa"; e a famigerada "Passeata contra a guitarra 
${ }^{9} c f$. Alves (2011) e Tinhorão (1998).

${ }^{10}$ As "Músicas de Festival" assim denominadas por concorrerem nos festivais competitivos promovidos pela emissora televisiva Record são os maiores emblemas dessa estratégia composicional. De Edu Lobo a Geraldo Vandré passando por Chico Buarque, Elis Regina, Jair Oliveira, entre outros, há um esforço sistemático em retomar uma suposta autenticidade imaculada brasileira, sem a "contaminação" da lógica mercantil da indústria. Não raro, esses artistas discorriam sobre os insumos "rústicos" "regionais" de suas composições, sempre aludindo a gêneros como a toada, o frevo, o baião, os sambas de morro e as marchas carnavalescas. Já em 2010 Geraldo Vandré viria a declarar sobre uma de suas mais célebres criações, cantada por Jair Rodrigues no Festival da Música Popular Brasileira em 1966: "Disparada é música brasileira, tem forma brasileira mais consequente com a tradição das formas de música popular, da moda de viola" (Programa Dossiê, Globo News).

11 Sobre esta dificuldade, elétrica", ocorrida em 1967. Por isso podemos falar em um embate mercantil-ideológico: é informado simultaneamente pela racionalidade do mercado e pela batalha em torno da identidade de um povo que se remaneja enquanto estrutura urbano-industrial e de serviços.

Neste contexto de embate, a intensificação do processo de industrialização do simbólico e a consequente expansão dos mercados de bens simbólicos evidenciam a força dos movimentos folcloristas, que acabam por potencializar o valor social atribuído a uma idealizada "pureza" e "autenticidade" nacional". Ancorado ainda nesse "estatuto de pureza nacional", um grupo de artistas que fica conhecido a partir da sigla MMPB — a "moderna música popular brasileira" - insere o caractere de conscientização política, criando uma hierarquia de legitimidades dentro da música nacional, em que brasileiro é sinônimo, a um só tempo, de engajamento político e "brasilidade", devendo remeter-se ao folclore idealizado de um Brasil rural ${ }^{10}$.

Jorge Ben Jor parece, com sua forma híbrida de criar, colocar-se numa posição fronteiriça e emblemática neste embate, daí decorre sua dificuldade em classificá-lo ${ }^{11}$ e também o fato de ainda hoje - não haver uma univocidade no recebimento de sua obra. A análise de Augusto de Campos (2008), que usa o termo intercomunicação, é bem ilustrativa neste sentido:

(...) há entre a "velha guarda", a "bossa nova" e a "jovem guarda" uma espécie de competição natural, amigável quando o denominador comum é a música "nacional" e apenas cordial quando a competição se dá entre a música "nacional" (tradicional ou nova) e música presumidamente "importada" ou "traduzida", embora possam ocorrer casos de intercomunicação, como o do cantor e compositor Jorge Ben, que passou do "Fino" para a "Jovem Guarda", do sambamaracatu para o "samba-jovem", e conseguiu ser (...) um dos maiores sucessos do programa de Roberto Carlos; por mais que o seu "iê-iê-iemanjá" desagrade aos puritanos da música nacional (...), a verdade é que Jorge Ben deglutiu o iê-iê-iê à sua maneira, sem trair-se a si próprio, e a prova é que o seu Chorava todo mundo já era um sucesso do "Fino" antes de ser "uma brasa" da Jovem Guarda (CAMPOS, 2008, p. 52).

Como já dito, o trânsito elaborado por Jorge Ben Jor não é feito de forma harmoniosa ou sem rusgas. Caetano Veloso, um dos cantores que admite ser epígono das criações de Ben Jor, é enfático ao ressaltar que "Jorge Ben, por ter se apresentado uma vez no Jovem Guarda, se vira posto no índex do Fino da Bossa' (VELOSO, 2008, p. 191). O próprio Jorge Ben Jor endossa a versão de Caetano, no documentário "Mosaicos: a arte de Jorge Ben Jor" (2008): "Eu tenho uma briga com a bossa nova, porque fui convidado pra fazer o Fino da Bossa. Mas aí eu recebi um convite do rei Roberto Carlos para participar da Jovem Guarda, que eu achei que ali era o meu lugar, onde eu cantei a primeira vez e me senti bem. Aí depois teve aquele problema, né? Nunca mais fiz outros programas a não ser a Jovem Guarda”.

A digressão feita até aqui dá indícios sobre o lugar da trajetória de Jorge Ben Jor na conformação do espaço social da música popular no país, em que a figura do cantor catalisaria o 
“(...) é possível perceber que a música deste compositorintérprete é permeada por diversas referências e isto faz com que seja difícil situá-lo em um gênero específico. Entendo que dentro desta riqueza de influências, percebem-se tanto elementos provenientes do samba e da bossa-nova, quanto da música internacional de massa - rock'n'roll e soul music predominantemente" (NASCIMENTO, 2008, p. 51)

12 Refiro-me especialmente à trajetória de Roberto Carlos, objeto da pesquisa de mestrado "A simplicidade de um rei: trânsitos de Roberto Carlos em meio à cultura popular de massa" (AMARAL, 2012), que a despeito do reconhecimento público de sua obra e de sua popularidade, sempre teve sua obra taxada - entre músicos, críticos e outros enquadradores da memória da música nacional - como popularesca, alienígena ou pastiche de música estrangeira. cruzamento entre gêneros tradicionais - à maneira do samba e da música etíope ensinada por sua mãe - e gêneros associados aos processos de mundialização e modernização, como o rock e o soul. Para figurar este cruzamento de gêneros, a discussão que se levantou acerca dos atravessamentos espaciais entre o "popular-nacional" e o “internacional popular" - subsidiada por Ortiz e Certeau — aponta para a interface que há entre o processo de industrialização do simbólico e a própria rearticulação da identidade nacional, agora articulada ao folclore aluvial das cidades.

Tudo indica que, a despeito de Jorge Ben Jor navegar por referentes simbólicos mundiais e nacionais, sua obra é considerada marcadamente autêntica; uma autenticidade imediatamente associada a noções como brasilidade e identidade nacional, mas simultaneamente global. Ora, levanta-se aqui uma questão fundamental: quais são os elementos da trajetória artística do cantor que fazem sua síntese musical sobreviver ao processo de seleção de uma série de gerações, sendo aceita como representante legítima da música nacional, enquanto outros artistas, a despeito de realizarem sínteses e hibridismos análogos, não obtêm tal aceite ${ }^{12}$

\section{Uma ruptura na "flecha do tempo"}

Para além dos atributos musicais que, até aqui, indicam que Jorge Ben Jor ocupa uma posição singular no espaço social da música do país - justamente em função da originalidade com que realiza o trânsito entre gêneros como o samba e o pop -, parece ser mister elencar os caracteres extramusicais que compõem a trajetória artística do cantor. Tais caracteres extramusicais aparecem como chaves de entendimento do forjamento de Jorge Ben Jor como símbolo de uma autenticidade simultaneamente nacional e global. Tal hipótese está esboçada na obra "O livro do disco: A Tábua de Esmeralda" de Paulo da Costa e Silva (2014), na qual o autor faz uma digressão histórica pelas décadas de 1960 e 1970 para mostrar que a eclosão mundial do movimento negro incide de forma direta sobre a criação artística do cantor — "todas as peças começavam a se mover no tabuleiro". Segundo ele,

(...) tudo isso tem relevância fundamental na compreensão dos núcleos poéticos contidos em A Tábua de Esmeralda [disco de 1974]. Um deles, absolutamente definidor do artista Jorge Ben, é a luta contra o racismo via afirmação da negritude: a elaboração de uma mitologia povoada de heróis negros e de uma identidade coletiva que não mais respeita os limites nacionais. Esse núcleo (...), anunciado desde os primeiros trabalhos de Ben, aparece com nitidez acabada e grande concentração de beleza em pelo menos duas canções do álbum: na obra-prima "Zumbi" e em "Brother", sintomaticamente composta na língua inglesa. De fato, entre as desigualdades legitimadas pela moldura do mundo moderno (no caso, pelo positivismo científico) nenhuma parecia mais inadmissível do que o racismo institucionalizado Não à toa, foi uma das primeiras a ser questionada. (...) Jorge Ben passa a atuar no fio da navalha histórica. Torna-se um verdadeiro "para-raio", nas palavras de Caetano Veloso, incorporando em sua figura e em sua música as descomunais forças geradas por uma sociedade em frenético movimento (SILVA, 2014, pp. 45-46) 
13 A obra "Identidade brasileira no espelho interétinico: essencialismos hibridismos em San Francisco" de Gustavo Lins Ribeiro (1998) pode ser uma chave para compreender a presença deste elemento "quente" entre aqueles que compõe a identidade nacional.

${ }^{14}$ Cf. Ortiz (2015)
A partir daí, pode-se propor que estava em questão, enquanto cantor, sua individualização, mas sobretudo enquanto artista negro: a afirmação da negritude aparece como uma de suas pautas temáticas e como referente musical, elucidado pelo uso das escalas menores, das pentatônicas do blues etc (NASCIMENTO, 2008). Outras temáticas, como a malandragem, o futebol e o carnaval também indicam sua vinculação às regiões do subúrbio carioca, de população majoritariamente negro-mestiça. As suas canções têm forte marca dançante e apelo coloquial. Não por acaso, durante a leitura de Nascimento (2008) e Oliveira (2012), as características mais exaustivamente utilizadas para descrever a forma de composição do cantor são: espontaneidade, displicência, indisciplina, inconstância, festividade.

Indícios dessas características são elucidados pelas próprias letras das canções, marcadas pelos desvios de métrica dos versos, uma característica que Nascimento (2008) chama de tematização, havendo primazia da narrativa sobre a melodia, mesmo que isto implique em encaixar uma quantidade de sílabas não comportada pela melodia. "Ouvindo Jorge Ben Jor cantar suas músicas, não raro, tenho a sensação de que determinados versos são maiores do que deveriam ser" (NASCIMENTO, 2008). O próprio cantor explica que, de fato, esta forma de compor é o seu apelo coloquial, a vontade de falar em cima da melodia: "Eu queria falar, como fosse um discurso, mas cantado. Eu sempre fiz isso" (Roda Viva, 1995). Por outro lado, seus refrães costumam resolver esta questão, com métricas bem elaboradas, letras pujantes e ritmo dançante: “Eu faço música alegre, né? As minhas músicas têm sempre final feliz" (Mosaicos, 2008).

Do ponto de vista sociológico, creio que há uma analogia entre o modo como o cantor atua na formulação de materialidades musicais, com forte marca dançante e apelo à irreverência coloquial, e a própria construção da identidade nacional, processo congruente à modernização brasileira ${ }^{13}$. Jorge Ben Jor conjuga os padrões da racionalidade tecnomercantil da cultura industrializada, com a indisciplina e regras mais maleáveis no tangente à composição e à interpretação. Conjuga o intimismo civilizado da bossa nova à expansividade de suas canções dançantes/festivas. O trânsito em polos aparentemente tão opostos operado pelo cantor coloca em cheque a concepção linear de tempo que orientou o projeto de modernidade universalizante cuja matriz encontra-se na Europa do século XIX, quando o industrialismo é tomado como condição sine qua non para o progresso ${ }^{14}$. Assim, a música de Jorge Ben Jor pode ser tomada como heurística daquilo que Ortiz (2015) chamará de "quebra da flecha do tempo" para indicar a impossibilidade de realização da modernidade enquanto rede de sentido capaz de integrar esferas tão diversas quanto arte e política. Com isso, progresso tecnológico e econômico não pode ser imediatamente articulado, de forma causal, às artes que eventualmente aparecerão para elucidar as fissuras da modernidade. 
${ }^{15} C f$. Weber (2004).

16 A expansividade e o apelo coloquial das canções de Jorge Ben Jor parecem ir de encontro às buscas estéticas empreendidas pelos músicos da bossa nova e da pelos músicos da bossa nova e da MPB, marcadas pela consonância em relação a um modelo civilizacional ocidental cujo cerne está no autocontrole, na contenção dos impulsos e emoções espontâneas, no controle dos sentimentos, na ampliação do espaço mental levando em conta o passado e o presente: enfim, "uma mudança civilizadora "no mudança civilizadora no comportamento" (ELIAS, 1993, p. ário europeu de "modernidade".

${ }^{17}$ Gilroy (2012) propõe que as palavras prolongadas por melismas, complementadas pelos gritos e grunhidos típicos do modalismo africano, fazem parte de uma política que, a despeito de desvelarem desejos e ações sociais qualitativamente novos de uma "comunidade racial", apresenta-se como resistência em relação à situação de opressão encontrada no passado escravocrata. O prolongamento vocálico via melisma seria, de acordo com sua interpretação, uma tática indicativa do poder de resistência da população negra
Em outras palavras, diríamos que a música de Jorge Ben Jor é "encantada", em contraponto ao processo de desencantamento do mundo que acometeria o imaginário civilizatório e modernizante ocidental $^{15}$. Ou seja, sua criatividade artística é eivada por um misticismo incivilizado e pelo afrouxamento dos mecanismos de autorregulação típicos do processo civilizador eliasiano ${ }^{16}$, o que pode ser elucidado pelos desvios de métrica, pelo vínculo com o imaginário medieval e com a alquimia, pelo uso de dissonâncias, melismas $^{17}$ e pela própria afirmação da negritude. Ao falar do "imaginário" que percorre as composições de Jorge Ben Jor, Silva (2014, p. 19) afirma que “(...) trata-se de um imaginário marcado pela capacidade de crer nas coisas que é desconcertante para o espírito cético de nosso tempo. É como se o inconsciente vivesse livre de qualquer tipo de censura".

Os caracteres negros entram neste rol de elementos "antimodernos" por fazerem frente à ideologia do embranquecimento que, pelo menos até a primeira metade do século $\mathrm{XX}$, tomava a população negro-mestiça como componente incivilizada de nossa identidade em contraposição à população branca de origem europeia, o "elemento civilizador". O embranquecimento poderia ser entendido, aqui, para além dos incentivos à imigração europeia, como a censura "modernizante" promovida aos elementos negros no período pós-abolicionista. As pesquisas de Florestan Fernandes (2008) são elucidativas desse fato, pois trazem à luz as "providências policiais" no sentido de dispersar e impedir a "revivescência" da cultura negra na cidade de São Paulo, sob pretexto de manutenção da ordem e da "moralidade dos costumes". Assim, a ideologia do embranquecimento verificada entre os membros da intelligentsia brasileira no final do século XIX e nos primeiros decênios do século $\mathrm{XX}$ contrapunha brancos e negros como análogos de uma suposta contraposição entre modernidade e tradição (SCHWARCZ, 1993).

Seguindo esta linha argumentativa, dizemos que Jorge Ben Jor é figuração do processo de revivescência de uma dimensão onírico-mítica e festiva que tensiona uma suposta "linha evolutiva" da música brasileira - termo utilizado por Caetano Veloso, denotando uma historicidade linear que se inicia com a bossa nova, passa pela MMPB e pela Jovem Guarda, e chega à "tropicália" (VELOSO, 1966). Ao unir o "primitivo" e o "moderno" - como sugere o texto de apresentação de seu primeiro disco, escrito por Armando Pittigliani —, Jorge Ben Jor não apenas apresenta-se como elucidativo de processos globais que questionarão a primazia da racionalidade como pilar da modernidade ${ }^{18}$, como também atua na formulação ou retomada de tradições recalcadas que passarão a compor algumas das imagens mais fortes do que chamamos de "brasilidade". Uma série de práticas que tentou-se suplantar, tais como a religiosidade, a expansividade dos movimentos corporais e o samba, outrora associados à incivilidade e tomadas em função de sua não consonância com o ideário modernizador de matriz europeia, são ressignificadas na obra do cantor. Daí a perenidade de sua obra 
que, impossibilitada de bradar em favor de seus direitos frequentemente violados, utiliza-se de artifícios nãoverbais como as danças, as encenações e o canto melismático para questionar a condição de opressão e subalternidade. Afinada com esse diapasão, sua análise indica que esse cantar é um dos elementos responsáveis por erigir um imaginário antimoderno, uma contracultura que reconstrói a própria genealogia do

"Atlântico Negro" — uma esfera pública própria da população negra - , revelando as fissuras internas no conceito de modernidade.

${ }^{18}$ Sobre este assunto, é válida a leitura da obra "Cosmopolis: the hidden agenda of modernity", na qual seu autor, Stephen Toulmin (1990), argumenta que a geração do período pós-guerra, especialmente a partir da década de 1960, se reconecta com valores adormecidos ou recalcados - durante $\mathrm{o}$ processo de modernização europeia. A modernização de matriz cartesiana, calcada no ordenamento racional da vida, viria a repudiar tudo aquilo que nela não se encaixava: a enquanto símbolo de uma autenticidade nacional que é, a todo instante, acionada pelo cantor a partir da retomada da cultura de matriz afro-brasileira.

\section{Considerações finais: um problema de enquadramento}

A despeito do caráter incipiente das reflexões apresentadas até aqui, a expectativa desta comunicação é contribuir com a discussão sobre a cultura popular no Brasil e na América Latina, destacando a relevância dos grandes ídolos de massa para esta discussão teórica. Araújo (2010) preocupa-se em mostrar a carência de trabalhos a este respeito a partir das noções de memória e esquecimento. Segundo este autor, no campo da música brasileira, a memória se apresenta como objeto de disputa e, com isto, apresenta seus enquadradores: críticos, pesquisadores, historiadores, musicólogos. São estes enquadradores de memória que parecem definir o que se tornará objeto de pesquisa. Neste sentido é que Araújo (2010) aponta a carência de trabalhos sobre algumas faces da cultura popular de massas no Brasil como resultado da preferência musical desses enquadradores da memória da musica brasileira que são, em sua maioria, pertinentes a uma classe média de formação universitária. Isto justifica a grande quantidade de trabalhos - dissertações, teses e livros - sobre Chico Buarque, Caetano Veloso, João Gilberto, a Bossa Nova, a Tropicália.

Por outro lado, justifica também a quantidade pequena de trabalhos sobre os artistas que não se enquadram nesta "memória oficial”, caso do cantor Jorge Ben Jor. É o que fica claro na irresolução do trabalho de Nascimento (2008) que, ao tentar enquadrá-lo em diversos gêneros musicais, conclui que sua obra apresenta traços que poderiam perfilá-lo a diversos estilos. De forma semelhante, Silva (2014, p. 48) aponta que o cantor se apropriou de um "novo caldo de cultura" temperado pela Jovem Guarda de Roberto e Erasmo Carlos e pelo tropicalismo de Caetano Veloso "sem estar propriamente filiado a qualquer grupo". O caso de Jorge Ben Jor é então emblemático, pois é "desenquadrado", transitando por vários meandros da música popular — desde as marchinhas, sambas-canções, boleros e bossa nova, até chegar ao rock e à "black music" de caráter internacional popular - sem, no entanto, filiar-se ou criar raízes em qualquer um deles.

Assim, de alguma maneira, essas reflexões - que compõem a parte inicial de uma tese de doutoramento - sugerem o "fim da história da música brasileira", tal qual faz Hans Belting (2012) ao propor o "fim da história da arte". Isto não significa que a música brasileira deverá deixar de ser historicizada. Ao contrário, ao propor o "fim da história da música brasileira", o que se quer é fazer a história de faces negligenciadas em nosso rol de artistas, ou seja, retomar a história não contada daqueles que não estão enquadrados 
emoção, o corpo, o "encantamento". Ou seja, tudo aquilo que "não podia ser controlado". Segundo o Toulmin, a realidade apresentada pelas Guerras Mundiais, forjadas em nome da racionalidade moderna, fomenta naquela geração a necessidade de retomar os valores humanistas do renascimento. Daí o surgimento de um movimento negro de dimensões globais no esquema classificatório da "história oficial". Em outras palavras: “o discurso do 'fim' não significa que 'tudo acabou', mas exorta a uma mudança no discurso, já que o objeto mudou e não se ajusta mais aos seus antigos enquadramentos" (BELTING, 2012, p. 13).

Em nossa pesquisa bibliográfica preliminar, pudemos constatar a carência da qual falamos acima. Neste levantamento inicial, foram encontrados apenas dois trabalhos acadêmicos que tomam o cantor Jorge Ben Jor como tema: $(i)$ a dissertação de mestrado "Para animar a festa: a música de Jorge Ben Jor", de Alam D’Ávila do Nascimento (2008) e (ii) o artigo “África Brasil: uma análise midiática do álbum de Jorge Ben Jor”, de Luciana Xavier Oliveira (2012). Embora o surgimento recente de trabalhos sobre o cantor seja indício do interesse em escrever sobre nuances negligenciadas de nossa música, eles recaem, ambos, no esforço irresoluto de enquadrar Jorge Ben Jor numa história da música brasileira pretensamente universal e totalizante, o que significaria adequá-lo a suas regras e modelos estético-musicais. Por outro lado, a pesquisa ora proposta apresenta o cantor em questão como polo oposto dos enquadramentos oficiais, pois ele despede-se dessa consciência histórica linear que poderia constranger-lhe e cercear-lhe a espontaneidade criativa, libertando-se descompromissadamente das amarras e da rigidez dos gêneros musicais. Deste modo, o trabalho apresentado buscou inserir-se nesta lacuna referente à conformação do espaço da música popular no Brasil, propondo uma história dos “desenquadrados" que, justamente em função do "desenquadramento", tornam-se emblemas de autenticidade e originalidade.

\section{Referências Bibliográficas}

ADORNO, Theodor; HORKHEIMER, Max. A indústria cultural: o esclarecimento como mistificação das massas. In ADORNO,

Theodor; HORKHEIMER, Max. Dialética do esclarecimento: fragmentos filosóficos. Rio de Janeiro: Jorge Zahar Ed., 1985. ALVES, Elder P. Maia. A economia simbólica da cultura popular sertanejo-nordestina. Maceió: EDUFAL, 2011.

2012. A sociologia de um gênero: o baião. Maceió: EDUFAL,

ALONSO, Gustavo. Simonal: quem não tem swing morre com a boca cheia de formiga. Rio de Janeiro: Record, 2011.

AMARAL, Marcos Henrique da Silva. A simplicidade de um rei trânsitos de Roberto Carlos em meio à cultura popular de massa.

Dissertação (Mestrado em Sociologia). Universidade de Brasília, Brasília, 2012

ARAÚJO, Paulo Cesar de. Eu não sou cachorro, não: música popular cafona e ditadura militar. Rio de Janeiro: Record, 2010. BELTING, Hans. O fim da história da arte. São Paulo: Cosac Naify, 2012.

CAMPOS, Augusto de. Balanço da bossa e outras bossas. São Paulo: Perspectiva, 2008

CERTEAU, Michel de. A invenção do cotidiano: 1 . artes de fazer. Petrópolis: Vozes, 1994.

ELIAS, Norbert. Introdução a Sociologia. Lisboa: Edições 70, 1970. 1993 O processo civilizador: 2. Rio de Janeiro: Jorge Zahar Ed.

. Mozart: sociologia de um gênio. Rio de Janeiro: Jorge Zahar Ed., 1995.

FERNANDES, Florestan. A integração do negro na sociedade de classes, vol. 1: ensaio de interpretação sociológica. São Paulo: Globo, 2008. 
GIDDENS, Anthony. As consequências da modernidade. São Paulo: Editora UNESP, 1991.

GILROY, Paul. O Atlântico Negro: modernidade e dupla consciência. São Paulo: Editora 34; Rio de Janeiro: Universidade Cândido Mendes, Centro de Estudos Afro-Asiáticos, 2012.

LOWENTHAL, Leo. Historical perspectives of popular culture.

American Journal of Sociology, The University of Chicago Press, v. 55, n. 4, p. 323-332, jan. 1950. Disponível em:

<http://www.jstor.org/stable/2772293>.

MARTIN-BARBERO, Jesús. Dos meios às mediações

comunicação, cultura e hegemonia. Rio de Janeiro: Editora UFRJ, 2009.

MIRA, Maria Celeste. O leitor e a banca de revistas: a segmentação da cultura no século XX. São Paulo: Olho d'Água/Fapesp, 2001. MORIN, Edgar. Cultura de massas no século XX: necrose. Rio de Janeiro: Forense Universitária, 2009.

NAPOLITANO, Marcos. A MPB na era da TV. In RIBEIRO, Ana Paula Goulart; SACRAMENTO, Igor; ROXO, Marco (orgs.). História da televisão no Brasil. São Paulo: Contexto, 2010. p. 85106.

NASCIMENTO, Alam D’Ávila do. Para animar a festa: a música de Jorge Ben Jor. Dissertação (Mestrado em Música). Universidade Estadual de Campinas, Instituto de Artes. Campinas, SP, 2008. OLIVEIRA, Luciana Xavier. África Brasil (1976): uma análise midiática do álbum de Jorge Ben Jor. In Contemporânea: comunicação e cultura. Vol. 10. n. 1. jan-abr. 2012

ORTIZ, Renato. A moderna tradição brasileira: cultura brasileira e indústria cultural. São Paulo: Brasiliense, 2006.

Mundialização e cultura. São Paulo: Brasiliense, 1996

Um outro território. São Paulo: Olho d'Água, 1999.

Universalismo e diversidade. São Paulo: Boitempo, 2015.

SILVA, Paulo da Costa e. A tábua de esmeralda: e a pequena renascença de Jorge Ben (O livro do disco). Rio de Janeiro: Cobogó, 2014

TINHORÃO, José Ramos. História social da música popular brasileira. São Paulo: Editora 34, 1998.
TOULMIN, Stephen. Cosmopolis: the hidden agenda of modernity. Chicago: The University of Chicago Press, 1990.

ULHÔA, Martha Tupinambá. Nova história, velhos sons: notas para ouvir e pensar a música brasileira popular. Debates, v. 1, n. 1, p. 80101, 1997.

VELOSO, Caetano. Verdade tropical. São Paulo: Companhia das Letras, 2008.

WEBER, Max. A ética protestante e o "espírito" do capitalismo. São Paulo: Companhia das Letras, 2004

\section{Outras referências: vídeos, discos, filmes e notícias}

BEN, Jorge. Samba esquema novo. São Paulo: Philips, 1963. 1 disco sonoro, 33 1/3 rpm, estéreo, 12 pol.

BEN, Jorge. O homem patropi. Revista Trip, São Paulo, edição 183, 10 nov. 2009. Entrevista concedida a Pedro Alexandre Sanches. DOSSIÊ. Entrevista com Geraldo Vandré. Rio de Janeiro: Globo

News, 21 de setembro de 2010.

MOSAICOS. A arte de Jorge Ben Jor. São Paulo: TV Cultura, 2008 Disponível em: <http://sambarocknaveia.uol.com.br/2011/06/assistao-documentario-sobre-jorge-ben-jor/>.

PARELES, Jon. Pop: Jorge Ben of Brazil. New York Times, Nova York, 23 jul. 1986.

RODA viva. São Paulo: TV Cultura, 1995. Disponível em: <http://sambarocknaveia.uol.com.br/2011/06/assista-odocumentario-sobre-jorge-ben-jor/>.

VELOSO, Caetano. Que caminho seguir na música popular brasileira?. Revista Civilização Brasileira, ano 1, n. 7, mai. 1966, pp 375-385. Debate coordenado por Airton Lima Barbosa. 